\title{
MAPEAMENTO GEOAMBIENTAL COMO SUBSÍDIO À SELEÇÃO DE ÁREAS PARA IMPLANTAÇÃO DE CENTRAIS DE TRATAMENTO DE RESÍDUOS SÓLIDOS URBANOS: APLICAÇÃO AO MUNICÍPIO DE SANTA CRUZ DA CONCEIÇÃO-SP
}

\author{
GEOENVIRONMENTAL MAPPING AS A SUBSIDY FOR THE SELECTION OF AREAS FOR \\ IMPLANTATION OF URBAN SOLID WASTE TREATMENT CENTERS: APPLICATION TO THE \\ SANTA CRUZ DA CONCEIÇÃO MUNICIPALITY, SÃO PAULO STATE
}

\section{Hermes Dias BRITO¹, Fábio Augusto Gomes Vieira REIS ${ }^{2}$, Claudia Vanessa dos Santos CORRÊA ${ }^{1}$}

${ }^{1}$ Programa de Pós-Graduação em Geociências e Meio Ambiente, Instituto de Geociências e Ciências Exatas, Universidade Estadual Paulista - UNESP, Rio Claro (SP), Brasil. Email: hermes.dias@ unesp.br; claudiageobrax@ yahoo.com.br ${ }^{2}$ Departamento de Geologia Aplicada, Instituto de Geociências e Ciências Exatas, Universidade Estadual Paulista -UNESP, Rio Claro (SP), Brasil. Email: fabio.reis@ @rc.unesp.br

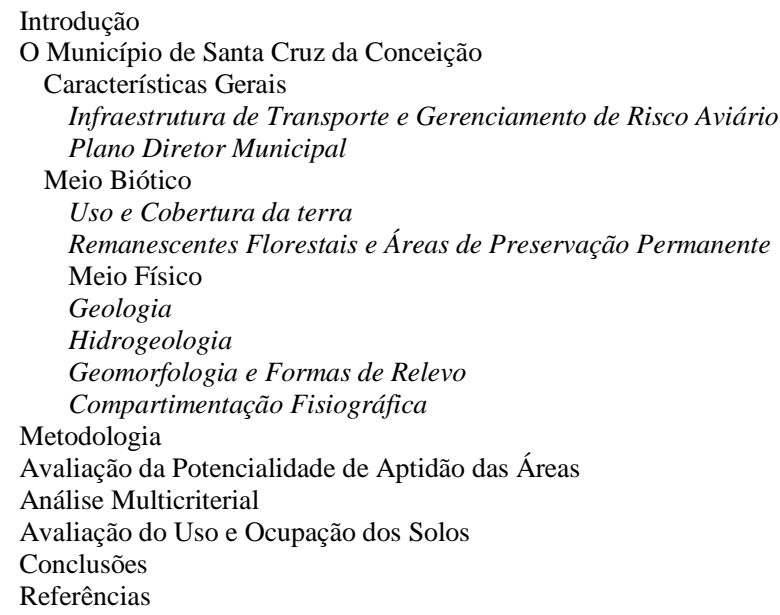

RESUMO - Este trabalho tem como objetivo apresentar e discutir o desenvolvimento de um mapeamento geoambiental voltado à seleção adequada de áreas para a implantação de Central de Tratamento de Resíduos Sólidos (CTRSs), tendo como foco de aplicação o município paulista de Santa Cruz da Conceição, que apresenta expressiva inconformidade ambiental em relação à gestão dos resíduos sólidos. A integração de informações obtidas com o levantamento bibliográfico efetuado, a geração de banco de dados (incluindo fatores físicos, biológicos e socioeconômicos) e a análise multicriterial em ambiente SIG conduziram à elaboração do respectivo mapeamento. Este teve como base fundamental estudo prévio de compartimentação fisiográfica da região do local, considerando-se principalmente a permeabilidade, resistência a erosão e estabilidade a movimentos gravitacionais, que foram integrados com dados de fragmentos de vegetação, declividade, áreas de gerenciamento de risco aviário de aeródromos regionais, informações do Plano Diretor e normas técnicas e legais. Entre os resultados obtidos, destaca-se a definição de áreas propícias à implantação de CTRSs, incluindo incineradores, e de aterros sanitários em valas e em camadas. Este estudo oferece elementos para discussões e tomadas de decisão relacionadas ao processo de implantação de Centrais de Tratamento de Resíduos e empreendimentos associados, sendo aplicável a outros municípios brasileiros.

Palavras-chave: Geologia de Engenharia, Ordenamento Territorial Sustentável, Análise Multicriterial, Estudo de Alternativas Locacionais.

\begin{abstract}
This study presents and discusses the development of a geo-environmental mapping focused on the proper selection of areas for the implementation of Solid Waste Treatment Center (SWTPs), with the application focus on the municipality of Santa Cruz da Conceição, a town in São Paulo State, which presents significant environmental nonconformity in relation to management solid waste and disposal of waste. The integration of information obtained from the literature performed, the generation of database (physical, biological and socio-economic elements) and multi-criteria analysis in GIS led to the preparation of this mapping. This work had as fundamental element a previously established physiographic compartmentalization of the area, and considered mainly the aspects of permeability, erosion resistance and stability to gravitational movements. Database was integrated with information on fragments of vegetation, slope, and poultry risk management areas in regional aerodromes, information on municipal laws, and legal and technical standards. Among the results obtained, there is, centrally, the definition of areas for setting up SWTPs, including incinerators and landfills (in ditches and in layers). This study provides elements for discussion and decision-making related to the implementation process of waste treatment plants and projects associated with them, being applicable to other municipalities.

Keywords: Engineering Geology, Sustainable Land Management, Multicriteria Analysis, Locational Alternatives Study.
\end{abstract}

\section{INTRODUÇÃO}

O Brasil colecionou, ao longo da história, experiências insatisfatórias relacionadas à

gestão de resíduos sólidos e, ainda hoje, está distante das condições ideais. Levando-se em 
consideração apenas os Resíduos Sólidos Urbanos (RSU), para o ano de 2015, $220 \mathrm{mil}$ toneladas diariamente foram geradas, e aproximadamente $41,3 \%$ desses resíduos foram encaminhados para lixões e aterros controlados espalhados pelo território brasileiro (ABRELPE, 2016).

No Estado de São Paulo, 54\% dos municípios apresentaram qualidade ineficiente de gestão de resíduos e apenas $2 \% \quad(9$ municípios) apresentam boas práticas de gestão (Perez, 2013).

Diante deste cenário, foi implementada em 2010 a Lei Federal $\mathrm{n}^{\circ} 12.305$ (Política Nacional de Resíduos Sólidos), a qual estabeleceu diretrizes que devem ser adotadas para o gerenciamento dos resíduos sólidos no Brasil, que ressaltam a importância da hierarquização das ações de manejo e passaram a ter aplicação obrigatória em todo país (BRASIL, 2010).

Para auxiliar no cumprimento da legislação por parte dos agentes públicos e privados, foram estabelecidas as Centrais de Tratamento de Resíduos Sólidos (CTRSs), que podem ser definidas como complexos industriais formados por um conjunto de instalações com diferentes funções, capazes de transformar matéria-prima (resíduos sólidos) em produtos comercializáveis após tratamento específico.

Este sistema, integrado com diferentes unidades, favorece a economia de energia e reduz gastos com transporte, realizando o aterramento dos rejeitos de forma ambientalmente adequada, quando inclui em seu projeto um aterro sanitário.

As técnicas mais implantadas nos últimos anos para a recuperação, tratamento e disposição final de resíduos sólidos urbanos foram os incineradores, plantas de gaseificação, usinas de reciclagem, biodigestores anaeróbicos, sistemas de tratamento mecânico biológico e aterros sanitários, que podem fazer parte de uma CTRS (Wilson, 2015).

Em vista da demanda por estas instalações, para que os municípios brasileiros se adequem às exigências legais, é necessário que os empreendedores executem estudos prévios à implantação das centrais, visando escolher, sob a perspectiva ambiental, os melhores locais para as suas implantações.

Em função de cada município apresentar em seu espaço geográfico características distintas e heterogêneas em relação aos meios físico, biótico e socioeconômico, é necessária a realização de estudos ambientais que classifiquem as partes territoriais segundo suas aptidões, norteando a iniciativa pública e privada na escolha das melhores áreas para determinada atividade.

Desta maneira, o estudo de alternativas locacionais diminui os possíveis danos ambientais e amplia o alcance dos benefícios, fazendo prevalecer maior harmonia entre o meio ambiente e diversos empreendimentos.

Neste contexto, destaca-se como uma ferramenta de avaliação e planejamento o mapeamento geoambiental, que tem como objetivo a compartimentação do território com base nas características do meio físico, suas inter-relações com o meio biológico e com as atividades antrópicas, colocando em evidência as suas potencialidades ou restrições de uso (Fiori, 2004).

Assim, com a finalidade de avaliar a potencialidade de aptidão de áreas municipais passíveis em receber uma Central de Tratamento de Resíduos Sólidos Urbanos, este trabalho visa desenvolver um mapeamento geoambiental em escala 1:50.000, tendo como referência o município de Santa Cruz da Conceição (SP). Para tal, foi considerada a possibilidade de implantação da um aterro sanitário, um incinerador, uma central de reciclagem, uma planta de gaseificação, um sistema de tratamento mecânico biológico e um biodigestor anaeróbico, por se tratar das técnicas mais adotadas para tratamento e recuperação de resíduos sólidos urbanos em escala global nos últimos anos.

\section{O MUNICÍPIO DE SANTA CRUZ DA CONCEIÇÃO}

\section{Características Gerais}

O município de Santa Cruz da Conceição, localizado no Estado de São Paulo, está inserido na mesorregião de Piracicaba, limitando-se com os municípios de Pirassununga, Leme, Corumbataí e Analândia.
Possui uma área de $150 \mathrm{~km}^{2}$, altitude de 635 metros e ocupa a área central da bacia hidrográfica do Ribeirão do Roque, afluente do Rio Mogi-Guaçu (IBGE, 2010) (Figura 1)

De acordo com dados do CEPAGRI (2015), o clima do município é enquadrado no tipo 
"Cwa" (clima temperado úmido com inverno seco e verão quente) (Köppen, 1948). Este tipo climático apresenta duas estações bem definidas: período chuvoso e quente, que ocorre entre outubro e março, e período seco com médias de temperaturas mais baixas, de abril a setembro (SIGRH, 2015).
Em relação aos ventos, predominam os ventos alísios, com velocidade média de $5,4 \mathrm{~km} / \mathrm{h}$, podendo atingir até $7 \mathrm{~km} / \mathrm{h}$ nos meses de máxima (Gomes, 2003). Dados eólicos de novembro de 2008 a abril de 2016 mostram que 35\% dos ventos no local sopram da direção noroeste $\left(315^{\circ}\right)$ (Brito, 2016; USP, 2016).

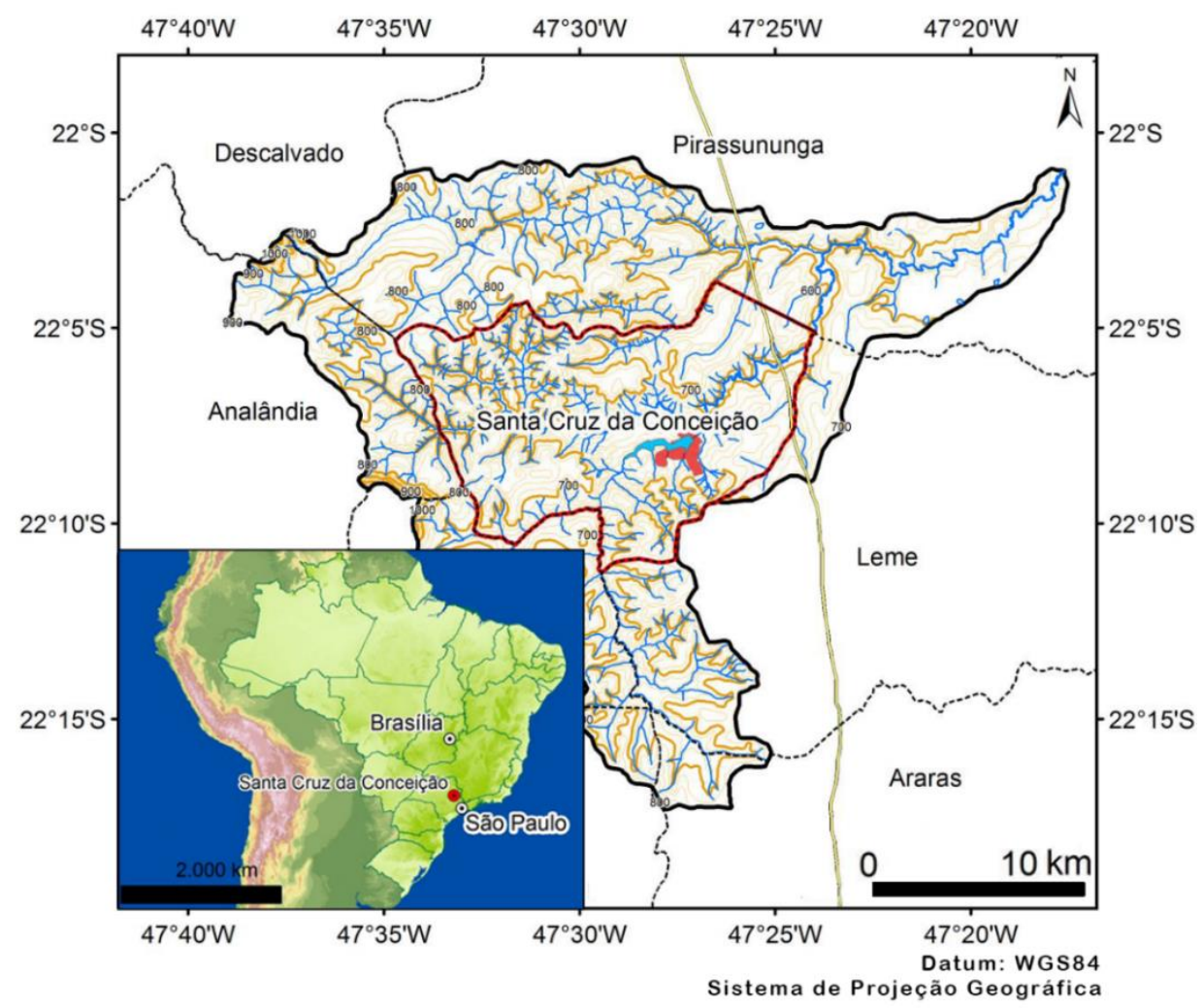

Figura 1 - Localização do município de Santa Cruz da Conceição (SP).

\section{Infraestrutura de Transporte e Gerenciamento de Risco Aviário}

Como principais rodovias de acesso à região, destacam-se a rodovia Anhanguera (SP-330) e a SP-225, que faz conexão com a Washington Luiz (SP-310), uma das principais rodovias do Estado de São Paulo. Ademais, o município é tangenciado por linha férrea no seu extremo leste.

Com relação ao transporte aéreo, existem dois aeródromos no município de Pirassununga, adjacente ao município de Santa Cruz da Conceição (ESRI, 2015). Segundo o Plano Básico de Gerenciamento do Risco Aviário (PBGRA), devem ser estabelecidas as delimitações das áreas de gerenciamento do risco aviário (AGRA) para aeródromos. A AGRA corresponde a uma área circular com centro no ponto médio da pista do aeródromo e raio de 20 $\mathrm{km}$. Esta também possui um setor interno, denominado de núcleo, com raio de $9 \mathrm{~km}$, e um setor externo, compreendido entre o núcleo e o seu limite (BRASIL, 2011) (Figura 2).

\section{Plano Diretor Municipal}

O Plano Diretor de Santa Cruz da Conceição, norteia o processo de ordenamento territorial através da delimitação das macrozonas rural e urbana, da área de expansão urbana, das zonas especiais de interesse ambiental, das paisagens edificadas e turísticas e das zonas de interesse industrial, dentre outras diretrizes.

Segundo o Plano Diretor, a macrozona urbana constitui a parte do território municipal onde a urbanização está consolidada e oferece infraestrutura urbana e disponibilidade de serviços públicos. Esta será ampliada ao longo do tempo pela incorporação das áreas contidas na área destinada à expansão urbana (Santa Cruz da Conceição, 2007).

As zonas especiais de interesse ambiental apresentam restrições de uso com o objetivo de preservar a paisagem e o meio ambiente, permitindo a ocupação qualificada e a oferta de espaços públicos adequados ao lazer da população (Santa Cruz da Conceição, 2007). 
$\mathrm{Na}$ zona especial de interesse turístico, destaca-se a obrigatoriedade de preservação de $30 \%$ dos espaços permeáveis, permitindo apenas uma taxa de ocupação de $50 \%$ do solo. A zona especial de paisagem edificada representa o espaço destinado a possíveis edificações verticais, região que recebe estímulos para que se intensifiquem atividades de comércio, serviços, lazer e usos institucionais (Santa Cruz da Conceição, 2007).

A zona de interesse industrial é composta e delimitada pelas áreas lindeiras das rodovias SP-193, SP-198 e SP-330, com distanciamento de 300 metros de cada lado dos pavimentos, formando corredores de interesse (Santa Cruz da Conceição, 2007).

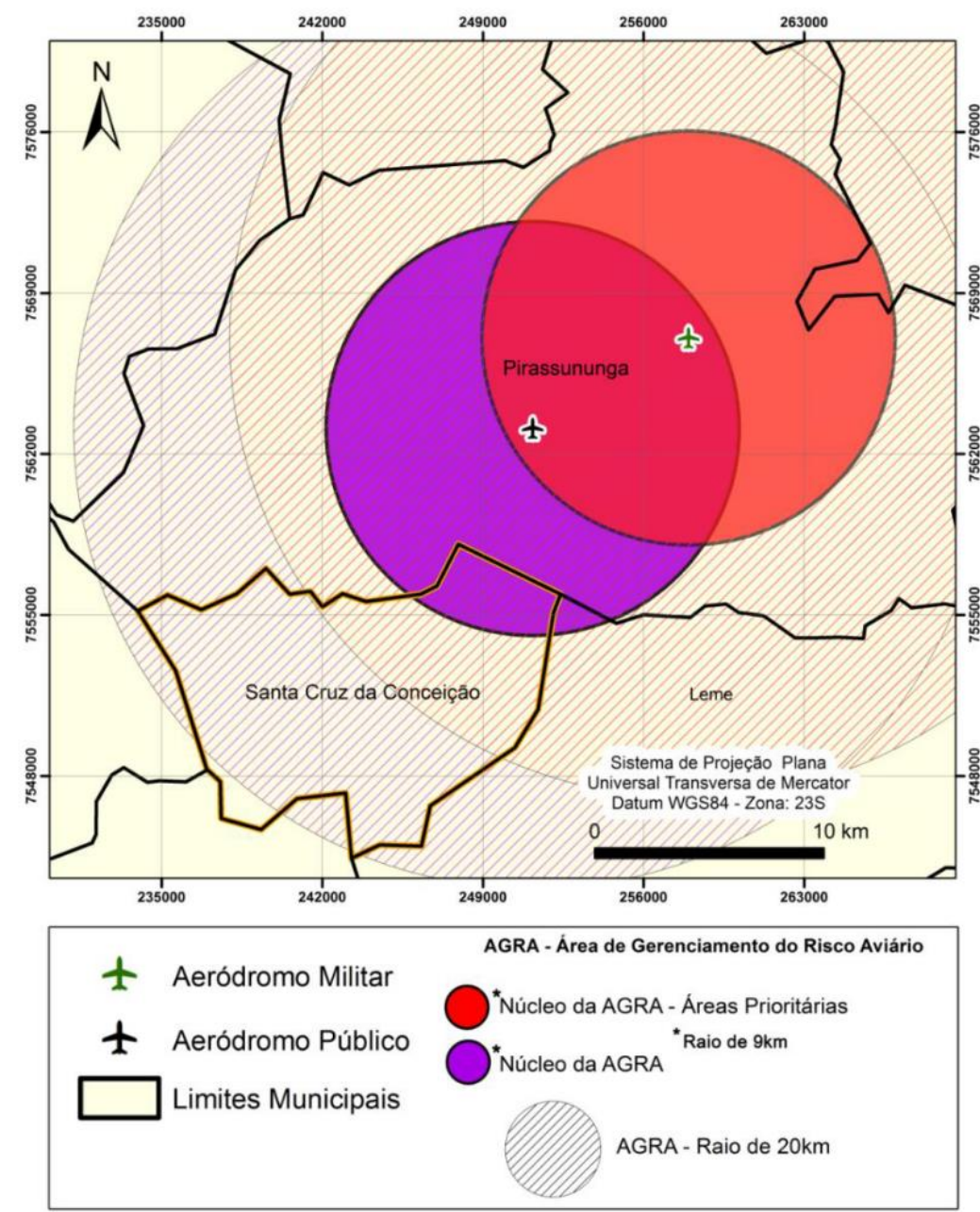

Figura 2 - Aeródromos próximos à Santa Cruz da Conceição e suas respectivas áreas de gerenciamento de risco aviário (AGRA). Fonte: ESRI (2015), BRASIL (2011), BRASIL (2015) e Perez (2013).

\section{Meio Biótico}

\section{Uso e Cobertura da terra}

Desde sua ocupação, a paisagem no município de Santa Cruz da Conceição sofreu grandes alterações com o uso da terra, especialmente em relação à cobertura original (Araújo, 2008).

Segundo o mesmo autor, os fragmentos florestais que ainda restam no local são caracterizados como vestígios do antigo ecótono entre Floresta Estacional Semidecidual (Mata Atlântica) e Cerrado, que ocupava a região no passado (Araújo, 2008).

Atualmente, os principais tipos de uso da terra encontrados no local são pastagens, cultura semi-perene (principalmente cana-de-açúcar) e fragmentos da vegetação original (Figura 3).

\section{Remanescentes Florestais e Áreas de Preservação Permanente}

No ano de 2015 existiam aproximadamente 33 $\mathrm{km}^{2}$ de remanescentes florestais no município, que recobria 22\% do seu território (Brito, 2016). Estes fragmentos distribuem-se principalmente ao longo dos canais de drenagem e, em alguns casos, são representados por áreas protegidas como Reserva Legal em propriedades rurais. As Áreas de Preservação Permanente (APPs), destinadas à proteção dos recursos hídricos superficiais (Lei Federal $n^{\circ}$ 12.651) (BRASIL, 2012), totalizam 17 $\mathrm{km}^{2}$ da área do município, o que compreende 11,5\% do seu território (Figura 4). 


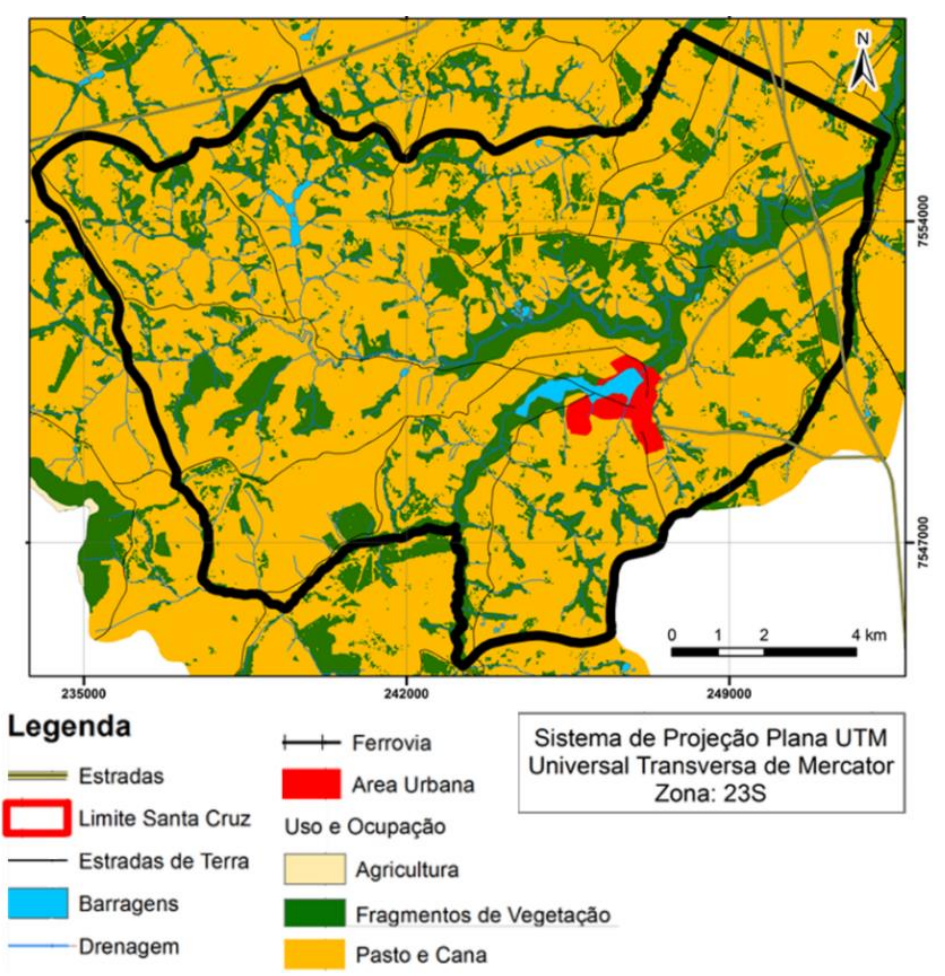

Figura 3 - Mapa de uso e ocupação da Bacia do Ribeirão do Roque. Fonte: Reis \& Cerri (2014).

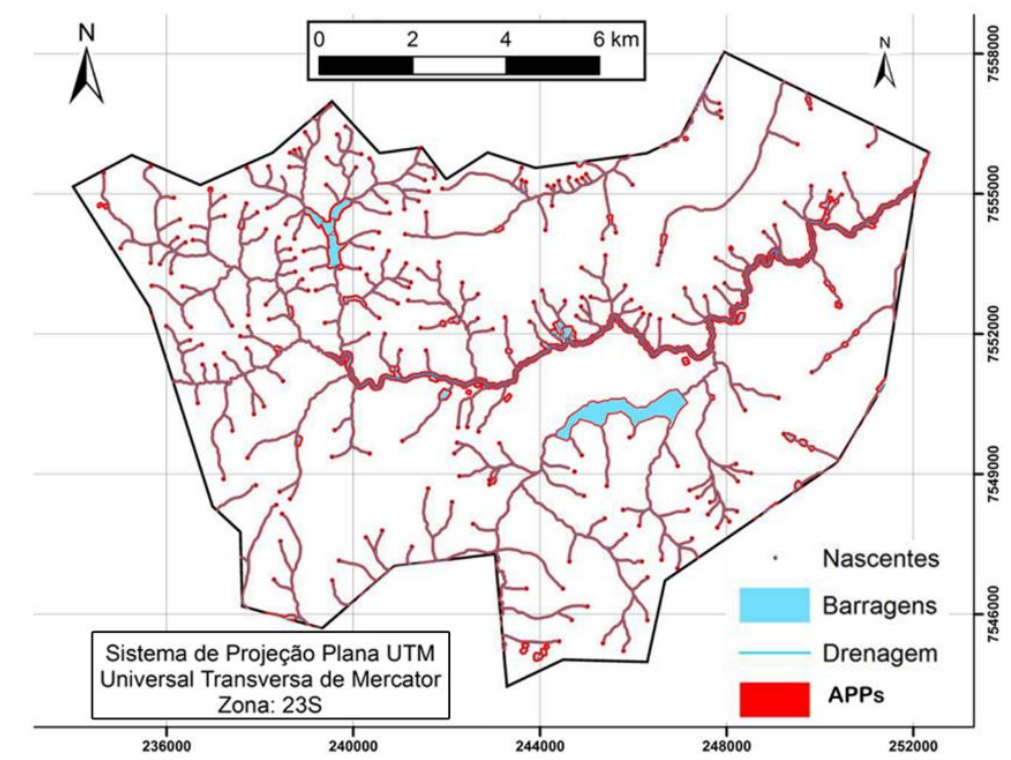

Figura 4 - Áreas de Preservação Permanente voltadas à proteção dos recursos hídricos. Fonte: Brito (2016).

\section{Meio Físico \\ Geologia}

Segundo Reis \& Cerri (2014), que realizaram o mapeamento geológicogeotécnico da bacia do Ribeirão do Roque, em escala 1:50.000, as unidades litológicas encontradas no local são arenitos da Formação Piramboia e manchas de arenitos da Formação Botucatu, na região oeste do município; siltitos e argilitos da Formação Corumbataí, na região central e leste; coberturas cenozoicas na região leste e sul e ocorrência de pequenas áreas com folhelhos calcários e sílex da Formação Irati e siltitos e arenitos da Formação Tatuí, na região leste.

Ocorrem intrusões de diabásio correlato à Formação Serra Geral no centro-oeste, oeste e sul do município. Em direção nordeste a planície aluvial atravessa o município (Reis \& Cerri, 2014) (Figura 5).

\section{Hidrogeologia}

Regionalmente, o município de Santa Cruz da Conceição está inserido nos Aquíferos do Guarani, do Diabásio, da Serra Geral, do Tubarão e do Aquiclude Passa Dois (IG, 1980; 1984) (Figura 6). 

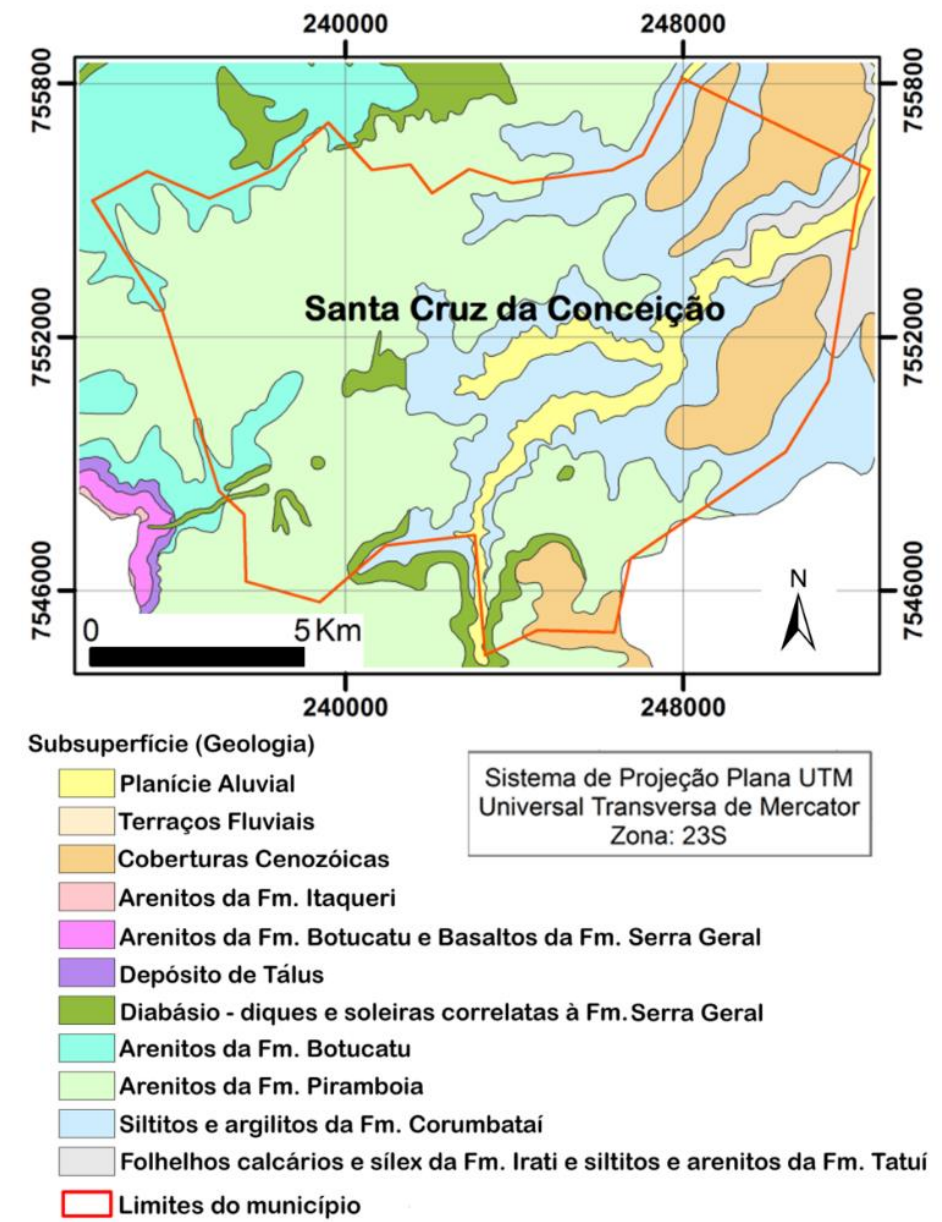

Figura 5 - Mapa geológico da Bacia do Ribeirão do Roque. Composição a partir de Reis \& Cerri (2014).

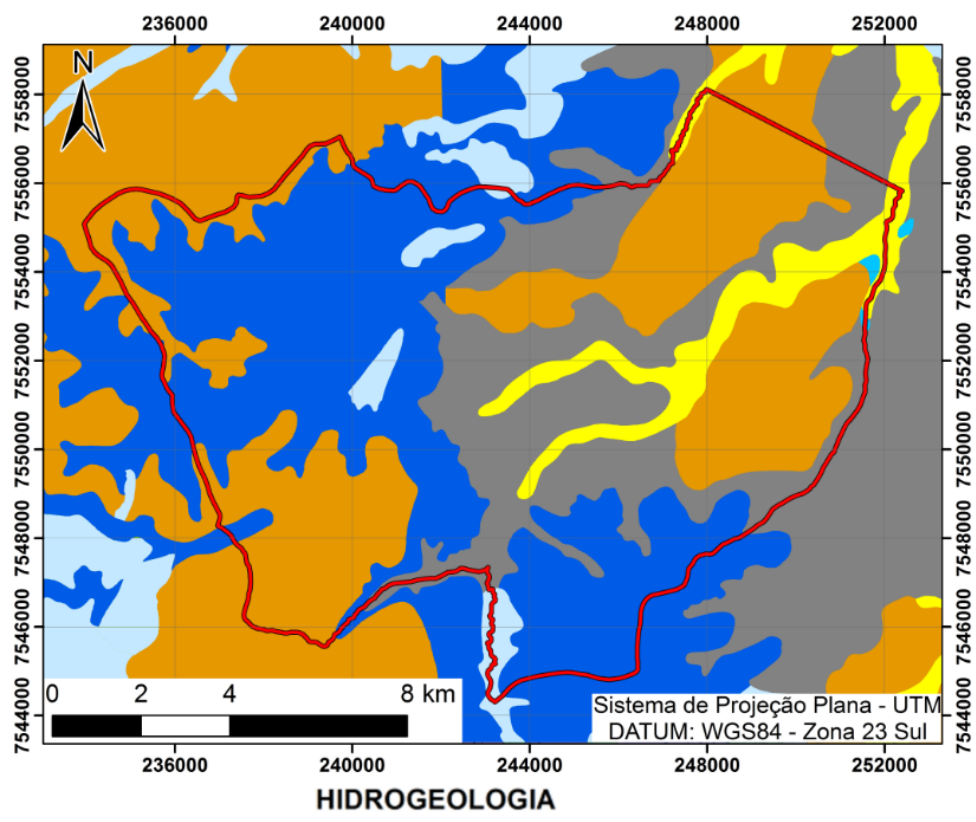

AQUICLUDE PASSA DOIS _ AQUIFEROS DE DEPÓSITOS TERCIÁRIOS AQUIFEROS FRATURADOS AQUIFERO GUARANI AQUIFERO TUBARÃO AQUIFERO SEDIMENTOS QUATERNÁRIOS

Figura 6 - Mapa das Áreas de Recarga de Aquíferos local. Fonte: IG (1980; 1984).

Particularmente importante é o Sistema Aquífero Guarani (SAG), um reservatório de água subterrânea composto por arenitos mesozoicos bastante homogêneos das formações
Piramboia e Botucatu, cobertos por espessas camadas basálticas que os confinam. Este reservatório possui boa permo-porosidade e uma elevada capacidade de armazenamento e 
fornecimento de água (OAS, 2005; Iritani \& Ezaki, 2012).

O Aquiclude Passa Dois é uma unidade hidrogeológica sedimentar que separa os Aquíferos Tubarão e Guarani, composto por folhelhos, siltitos, argilitos, calcários e dolomitos que ocorrem como camadas com diferentes espessuras, às vezes, ritmicamente intercaladas. Apresenta grande porosidade e baixa permeabilidade, o que o caracteriza como um meio relativamente impermeável (Karmann, 2000).

O Aquífero Tubarão é um aquífero sedimentar com ocorrência de siltitos, argilitos, folhelhos, arenitos muito finos, arenitos conglomeráticos e ritmitos. O aquífero em geral apresenta baixa produtividade de água para consumo (Iritani \& Ezaki, 2012).

De acordo com os mesmos autores, o Aquífero Diabásio é um aquífero fraturado, com extensão restrita e constituído de diabásios gerados a partir do resfriamento e solidificação do magma em subsuperfície. A circulação e o armazenamento da água subterrânea nesta unidade hidrogeológica está condicionada à ocorrência de fraturas geradas por esforços tectônicos decorrentes da movimentação da crosta terrestre.

O Aquífero Serra Geral é caracterizado como um aquífero fraturado constituído por uma sequência de derrames de lava vulcânica, que originaram as rochas basálticas (Iritani \& Ezaki, 2012).

\section{Geomorfologia e Formas de Relevo}

$\mathrm{Na}$ classificação de Ross \& Moroz (1997), Santa Cruz da Conceição está inserida na Depressão Periférica Paulista, especificamente na Depressão do Mogi Guaçu, cujos modelados dominantes são as colinas com topos amplos. Em relação as formas de relevo encontradas no local, a maior parte do território é composta por zonas de meia-encosta. Na porção leste e sul ocorrem relevos colinosos, encostas suaves, morrotes alinhados; em poucas áreas na porção sudoeste do município são encontradas encostas íngremes. Nas demais áreas ocorrem planícies aluviais (Reis \& Cerri, 2014) (Figura 7).

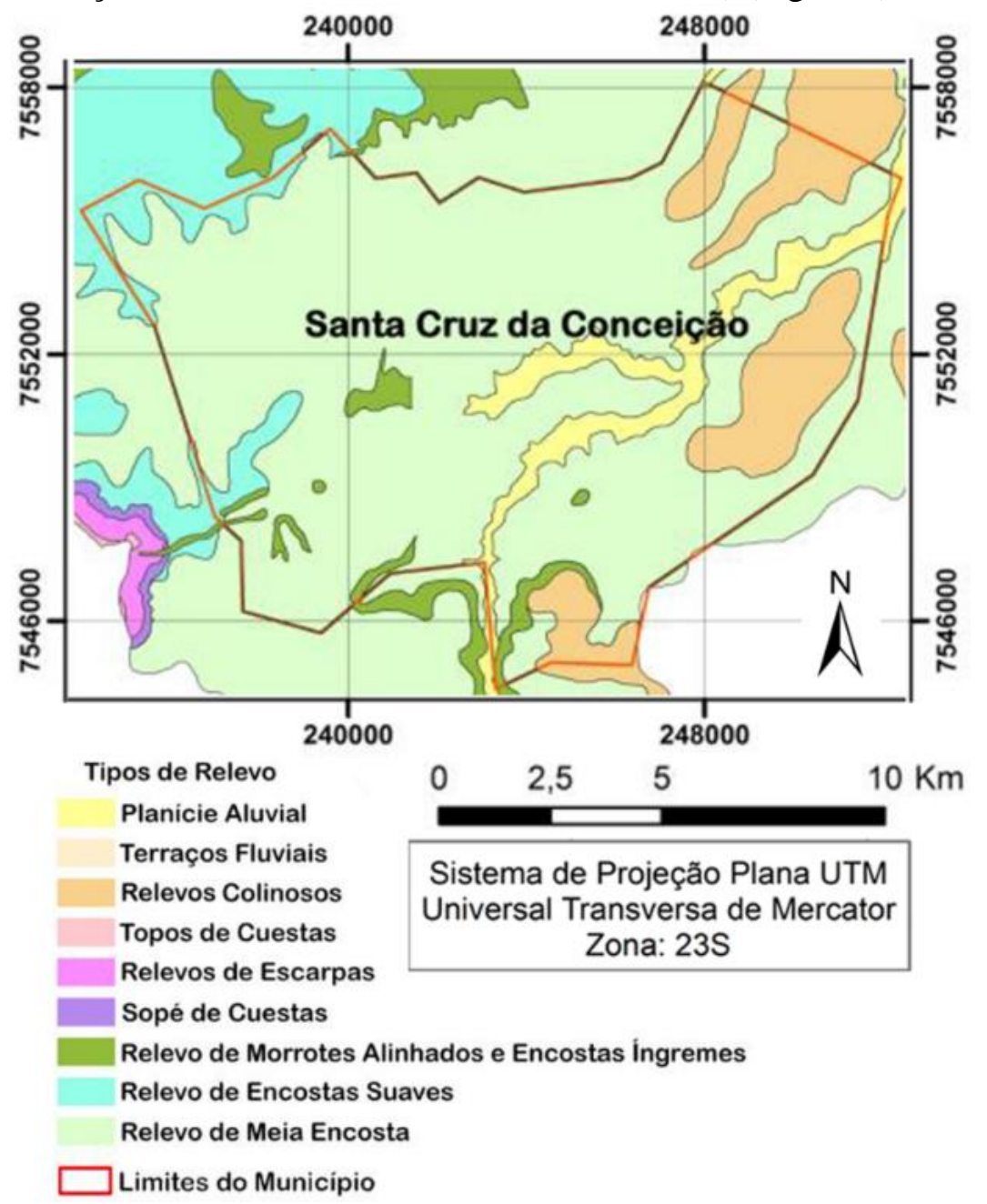

Figura 7 - Formas de relevo no município de Santa Cruz da Conceição. Composição com base em mapeamento elaborado por Reis \& Cerri (2014). 
As informações acerca da declividade apontam que essencialmente, o município é dominado por regiões com declividades que variam de $0^{\circ}$ a $5^{\circ}$ e regiões com declividades variando de $5^{\circ}$ a $17^{\circ}$ Em relação à altimetria, o mapa hipsométrico revela que a altitude no local varia entre 500 a 800 metros.

\section{Compartimentação Fisiográfica}

Baseando-se na metodologia proposta por Zaine (2011), Reis \& Cerri (2014) elaboraram a compartimentação fisiográfica da bacia hidrográfica do Ribeirão do Roque, na qual insere-se o município de Santa Cruz da Conceição (Figura 8).

No município são encontradas 7 unidades fisiográficas (unidades I, III, VI, VII, VIII, IX e $\mathrm{X})$, que reúnem os elementos constituintes do meio físico de acordo com suas semelhanças e diferenças, apontando as suas principais características geológico-geotécnicas, fragilidades e potencialidades diante qualquer intervenção antrópica (Oliveira, 2004) (Figura 9).

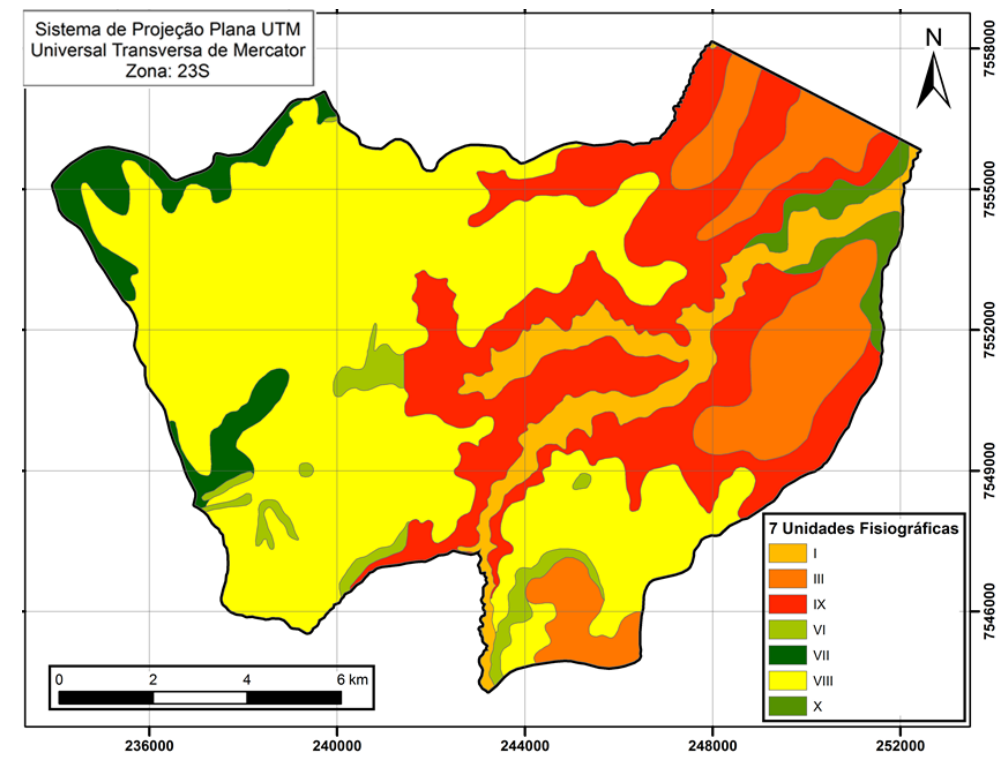

Figura 8 - Unidades fisiográficas em Santa Cruz da Conceição. Fonte: Reis \& Cerri (2014).

\section{METODOLOGIA}

A metodologia empregada para a seleção de áreas aptas à implantação de CTRSs no município de Santa Cruz da Conceição pode ser resumidamente descrita de acordo com as etapas abaixo (Figura 10). Para tal, foram obtidos os seguintes materiais cartográficos e produtos de sensoriamento remoto, georreferenciados no datum WGS84 com sistema de projeção plana UTM (Zona 23 Sul):

- Mapa de compartimentação fisiográfica incluindo informações geológicas, de formas de relevo, materiais e solos, permeabilidade, resistência à erosão e de processos de dinâmica superficial (Reis \& Cerri, 2014);

- Mapa de declividade, gerado a partir das cartas topográficas das Folhas Leme e Corumbataí, em escala 1:50.000 (IBGE, 1971a; 1971b);

- Mapa hidrográfico, representado pelas curvas de nível e hidrografia das cartas topográficas do IBGE em escala 1:50.000 (IBGE, 1971a; 1971b);
- Mapa com áreas de recarga de aquíferos, gerado a partir das informações das cartas geológicas das Folhas Leme e Corumbataí em escala 1:50.000 (IG, 1980; 1984);

- Mapa de áreas de preservação permanente (APP's) referentes à proteção de corpos hídricos, gerados a partir da base hidrográfica do IBGE (IBGE, 1971a; 1971b) e no enquadramento da norma brasileira (BRASIL, 2012);

- Mapa de remanescentes florestais de 2015, obtido através de fotointerpretação em imagens de satélite do Google Earth do ano de 2015;

- Mapas da área urbana atual e de expansão urbana elaborados através do Google Earth (2015) e Santa Cruz da Conceição (2007) e mapa com os aglomerados humanos regionais;

- Mapas com zonas de interesse municipal no escopo do Plano Diretor, incluindo áreas destinadas à expansão urbana e à implantação de indústrias, áreas de interesse ambiental e turístico, e macro zonas rural e urbana (Santa Cruz da Conceição, 2007); 


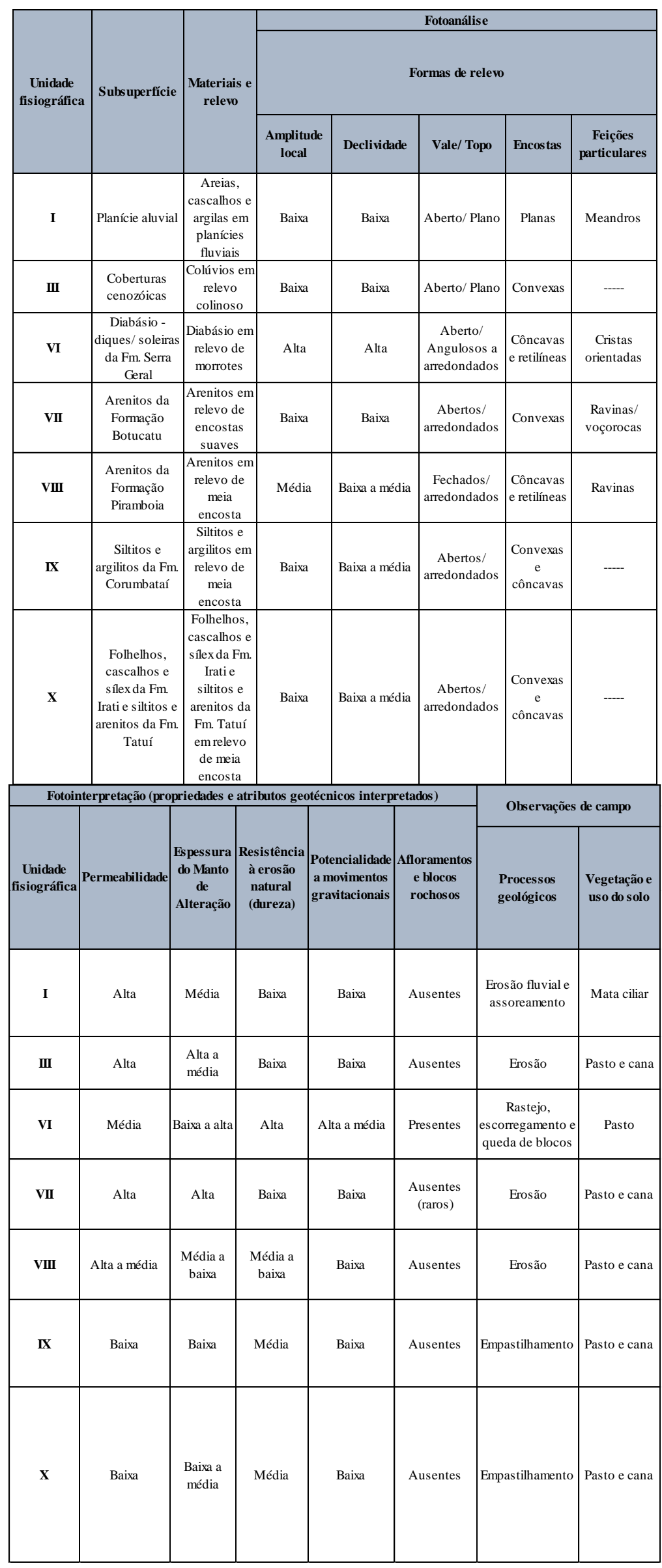

Figura 9- Caracterização geológica-geotécnica das unidades fisiográficas de Santa Cruz da Conceição. Fonte: Reis \& Cerri (2014). 


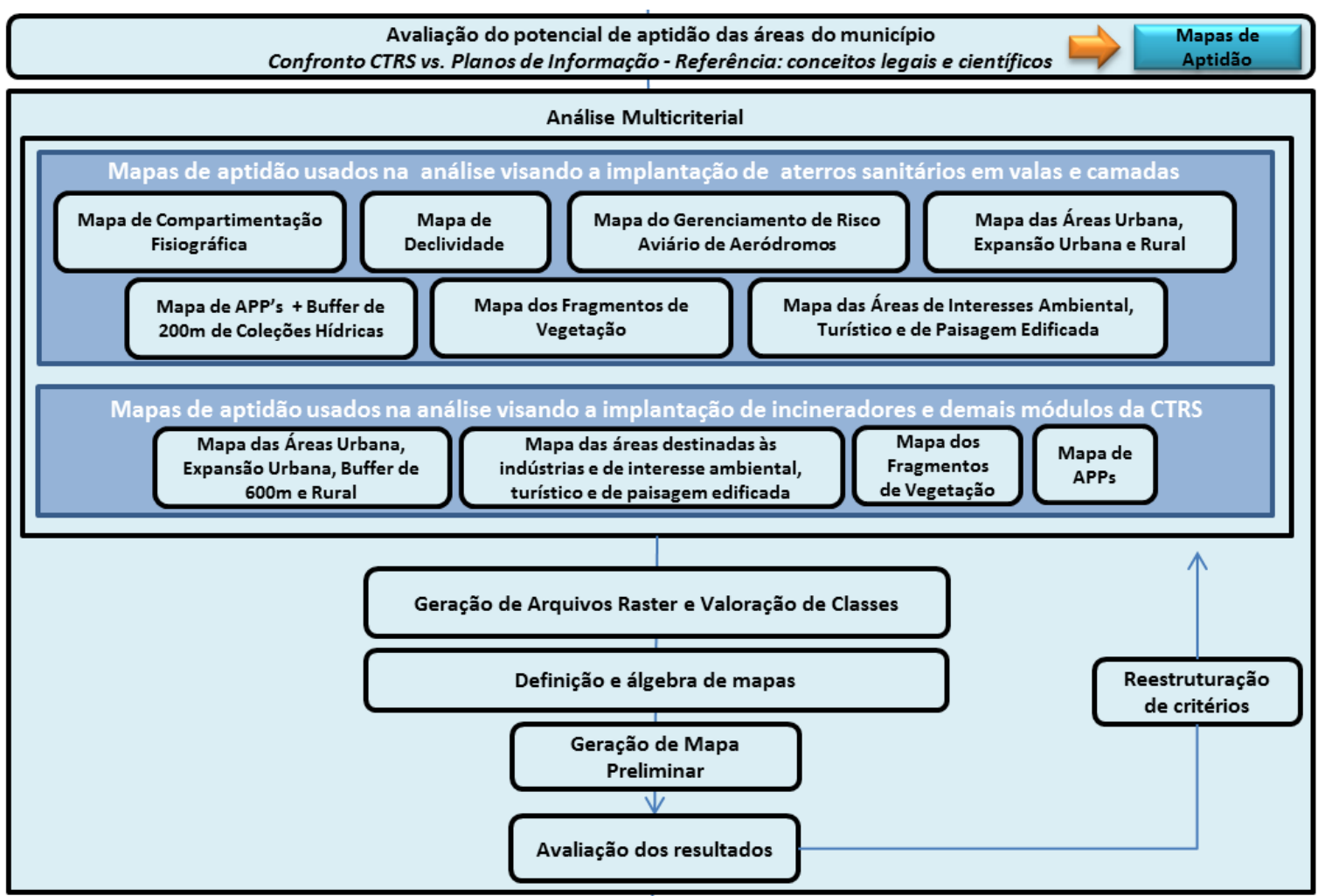

Geração dos Mapas de Potencialidade de Aptidão para implantação de aterros e incineradores (CTRS)

Avaliação do uso e ocupação do solo e direções dos ventos

Imagem de Satélite 2015

Direção do Ventos

Mapas Geoambientais Finais e Indicação de Locais Preferenciais para Implantação de Aterros e CTRSs

Figura 10 - Fluxograma das etapas de trabalho.

- Certificação de ausência de unidades de conservação na região, verificado junto ao Cadastro Nacional de Unidades de Conservação (MMA, 2016);

- Mapa regional com a infraestrutura de transporte terrestre (Reis \& Cerri, 2014; ESRI, 2015);

\section{AVALIAÇÃO DA POTENCIALIDADE DE APTIDÃO DAS ÁREAS}

Os níveis de potencialidade foram descritos e avaliados variando de baixo a alto. Assim, foram considerados os potenciais de impactos, vulnerabilidade e exigências de cada empreendimento avaliado (aterros sanitários em valas, aterros sanitários em camadas e incineradores) frente à cada variável consi-
- Mapa com as áreas de proteção de risco aviário de aeródromos próximos (ESRI, 2015; BRASIL, 2011; Perez, 2013);

- Mapa regional com informações de densidade demográfica nos raios de 100, 200 e $300 \mathrm{~km}$ a partir do município de Santa Cruz da Conceição (IBGE, 2010).

\section{ANÁLISE MULTICRITERIAL}

Em ambiente SIG (software Arcgis 10.1), foram realizadas as interpolações multicriteriais dos dados, baseadas nos levantamentos dos produtos cartográficos e de sensoriamento remoto. Assim, para a análise destinada à derada. Para a compartimentação fisiográfica, foram selecionados como parâmetros de referência as variáveis permeabilidade, resistência à erosão e susceptibilidade aos processos gravitacionais, obtido através da compartimentação fisiográfica elaborada por Reis \& Cerri (2014) (Figura 11). implantação de aterros em valas e em camadas, foram integrados os mapas de compartimentação fisiográfica, de declividade, de áreas preservação permanente e de proteção extra de recursos hídricos indicados pela NBR 15849 da ABNT 
(2010), de fragmentos de vegetação, mapa de gerenciamento de risco aviário de aeródromos, mapa das áreas urbanas, de expansão urbana e rural e das áreas de interesses municipais que estão presentes no Plano Diretor, incluindo as áreas destinadas às instalações industriais.
Cabe ressaltar que devido ao fato de aterros em valas e camadas apresentarem diferentes demandas quanto ao critério declividade, os valores das classes foram subdivididos em intervalos de 0 a $5^{\circ}$ (ideais para aterros em valas) e de 5 a $17^{\circ}$ (ideais para aterros em camadas) (Levine, 1996; Zuquette et al., 1994).

\begin{tabular}{|c|c|}
\hline Variável & Descrição dos critérios limitantes \\
\hline Declividade & $\begin{array}{l}\text { Ocorrência de processos dinâmicos (erosão e movimentos gravitacionais de massa (Brollo, 2001) } \\
\text { Considera-se ideais para aterros em valas declividades entre } 0 \text { a } 5^{\circ} \text { e para aterros em camadas } 5 \text { a } 17^{\circ} \\
\text { (Levine, 1996; Zuquette et al., 1994) }\end{array}$ \\
\hline \multirow{2}{*}{$\begin{array}{l}\text { Áreas de Preservação } \\
\text { Permanente }\end{array}$} & $\begin{array}{c}\text { Regiões que devem ter prioridade de conservação para que os corpos d'água e os recursos bióticos } \\
\text { sejam resguardados (Brasil, 2012) }\end{array}$ \\
\hline & $\begin{array}{l}\text { Distância minima de } 200 \text { metros de qualquer corpo hidrico ou curso d"agua para aterros sanitários } \\
(\mathrm{ABNT}, 2010) \text { e de } 150 \text { metros para incineradores (Ferretti \& Pomarico, 2012) }\end{array}$ \\
\hline $\begin{array}{l}\text { Fragmentos de } \\
\text { vegetação }\end{array}$ & $\begin{array}{l}\text { Regiões com prioridade de conservação e exclusas para implantação de CTRS (ABNT, 2010; Brasil, } \\
\text { 2012; Ferretti e Pomarico (2012) }\end{array}$ \\
\hline $\begin{array}{c}\text { Áreas de } \\
\text { gerenciamento de risco } \\
\text { aviário (AGRA) }\end{array}$ & $\begin{array}{l}\text { Locais onde devem ser evitadas a proliferação de aves, sendo necessária cautela na operação de } \\
\text { empreendimentos que possam atrair esses animais (Brasil, 2011) }\end{array}$ \\
\hline $\begin{array}{l}\text { Áreas urbanas e rurais } \\
\text { e de expansão urbana }\end{array}$ & $\begin{array}{l}\text { Aterros sanitários e incineradores devem estar localizados distante de núcleos populacionais (minimo de } \\
500 \text { metros para aterros e } 600 \text { metros para incineradores) pois podem trazer desconforto à população, } \\
\text { tanto na fase de implantação quanto a de operação (Ferretti e Pomarico (2012); ABNT, 2010; Cunha \& } \\
\text { Consoni, 1995; IPT, 1995; Brollo, 2001; IG, 1999; Proske et al.; 2005; Ersoy \& Bulut, 2008). }\end{array}$ \\
\hline \multirow{3}{*}{$\begin{array}{c}\text { Áreas de interesse } \\
\text { ambiental, turistico e } \\
\text { de paisagem edificada } \\
\text { (Santa Cruz da } \\
\text { Conceição, 2007) }\end{array}$} & $\begin{array}{c}\text { Áreas de interesse ambiental: restrições de uso com o objetivo de preservar a paisagem e o meio } \\
\text { ambiente, permitindo a ocupação qualificada e a oferta de espaços públicos adequados ao lazer da } \\
\text { população }\end{array}$ \\
\hline & $\begin{array}{l}\text { Áreas de interesse turistico: obrigatoriedade de preservação de } 30 \% \text { dos espaços permeáveis, } \\
\text { permitindo apenas uma taxa de ocupação de } 50 \% \text { do solo }\end{array}$ \\
\hline & $\begin{array}{l}\text { Área de paisagem edificada: espaço destinado a possiveis edificações verticais, região que recebe } \\
\text { estimulos para que se intensifiquem atividades de comércio, serviços, lazer e usos institucionais }\end{array}$ \\
\hline \multirow{2}{*}{$\begin{array}{l}\text { Áreas destinadas ao } \\
\text { uso industrial }\end{array}$} & $\begin{array}{l}\text { Locais que devem ser evitados para instalação de aterros sanitários por possuirem grande valor } \\
\text { imobiliário (Santa Cruz da Conceição, 2007) }\end{array}$ \\
\hline & $\begin{array}{l}\text { Incineradores podem ser implantados nos parques industriais do municipio, desde que as normas } \\
\text { especificas para emissão de poluentes sejam atendidas (Brasil, 2002) }\end{array}$ \\
\hline Direção dos ventos & $\begin{array}{l}\text { Avaliação da direção dos ventos devido à dispersão de poluentes por parte dos incineradores (Path, } \\
\text { 2005; Brasil 2002) }\end{array}$ \\
\hline Permeabilidade & $\begin{array}{l}\text { Vulnerabilidade à contaminação de águas subterrâneas, parâmetro considerado critico por diversos } \\
\text { trabalhos em relação à implantação de aterros sanitários (Cunha \& Consoni, 1995; Giusti, 2009; Gouveia } \\
\text { \& Prado, 2010; Zuquette et al., 1997; ABNT, 2010; IPT, 1995 }\end{array}$ \\
\hline Resistência à erosão & $\begin{array}{l}\text { Ocorrência de processos erosivos pode resultar no afloramento do lençol freático e, consequentemente, } \\
\text { em sua contaminação (IG, 1999; Brollo, 2001; Lino, 2007) }\end{array}$ \\
\hline $\begin{array}{l}\text { Movimentos } \\
\text { gravitacionais de } \\
\text { massa }\end{array}$ & $\begin{array}{l}\text { Os movimentos gravitacionais podem ocasionar instabilidade estrutural e afetar a segurança do aterro } \\
\text { sanitário e do incinerador (Brollo, 2001; IG, 1999; Lino, 2007; Ersoy \& Bulut, 2008; ABNT, 2010; } \\
\text { Zuquette et al., 1997; Cunha \& Consoni, 1995, Ferretti \& Pomarico, 2012) }\end{array}$ \\
\hline
\end{tabular}

Figura 11 - Variáveis e descrição dos critérios limitantes para implantação de empreendimentos existentes na CTRS

Os planos de informação supracitados foram transformados para arquivos em formato Raster com células de 5 x 5 metros através da ferramenta Feature to Raster. Em sequência, foi realizada a valoração das células unitárias com a ferramenta Reclassify. Assim, cada célula Raster pertencente a cada classe dos diferentes planos de informação receberam um valor de acordo com o nível de potencialidade de aptidão diante à implantação do respectivo empreendimento (Figuras 12 e 13).

Posteriormente, foi realizada uma álgebra de mapas através da soma (para aterros), e uma média ponderada entre os planos com classes valoradas em 5 e 10, seguida da soma dos demais planos, para os incineradores, pela ferramenta Raster calculator do ArcMap.

Os resultados foram a geração de três mapas de potencialidade segundo os critérios geoambientais. 


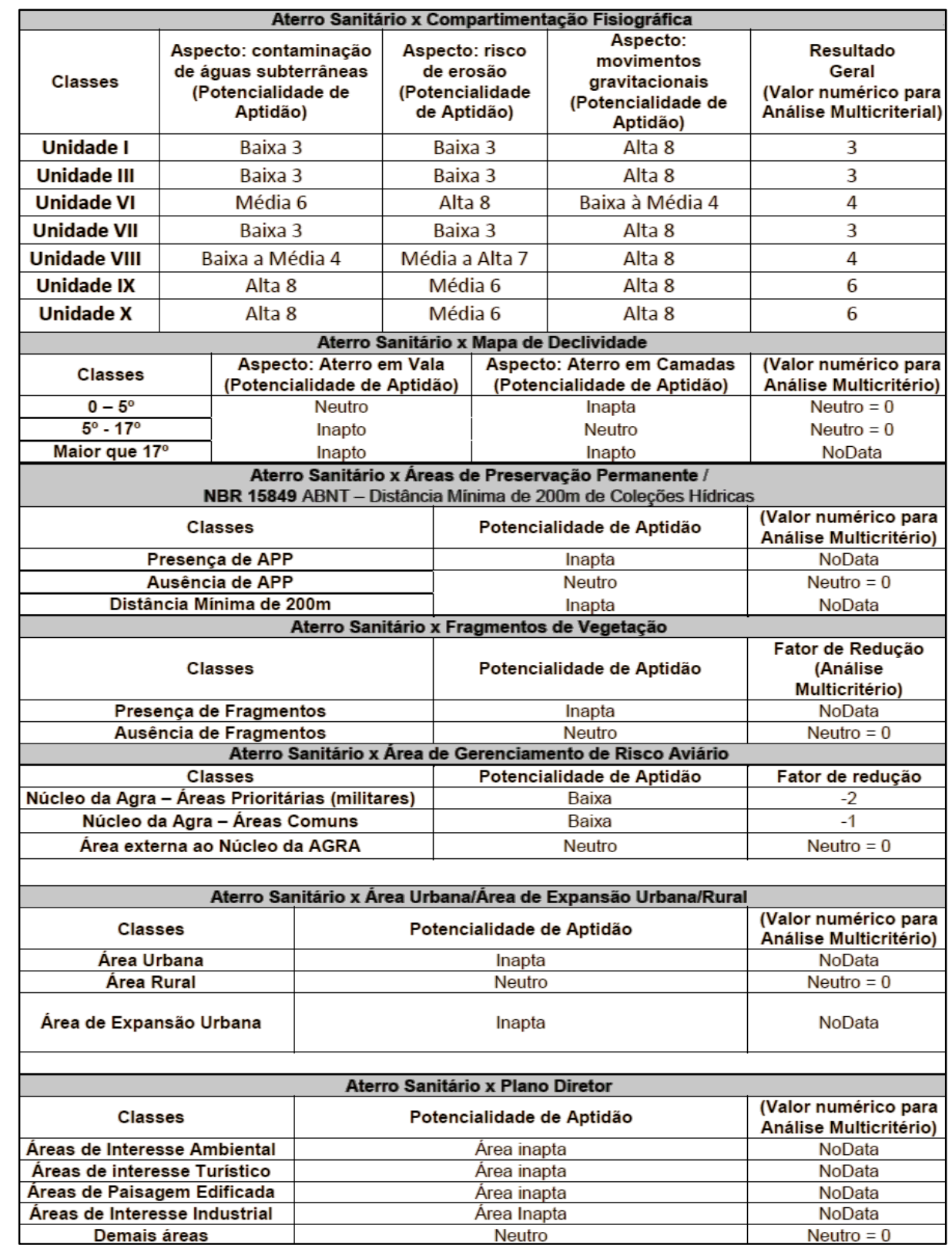

Figura 12 - Valoração numérica para análise multicriterial da potencialidade de aptidão das classes para aterros frente aos diferentes empreendimentos possivelmente existentes na CTRS

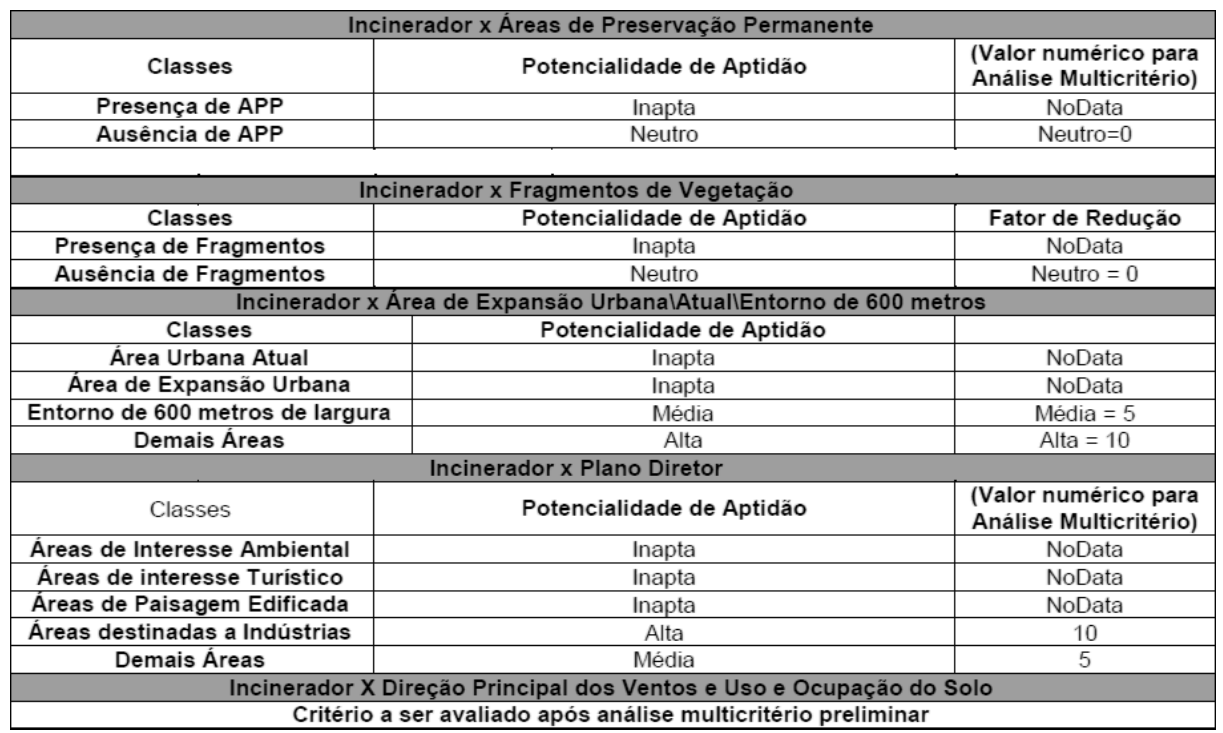

Figura 13 - Valoração numérica para análise multicriterial da potencialidade de aptidão das classespara incineradores frente aos diferentes empreendimentos possivelmente existentes na CTRS. 


\section{AVALIAÇÃO DO USO E OCUPAÇÃO DOS SOLOS}

A partir da indicação de áreas potenciais para a implantação de aterros e incineradores obtida na etapa anterior, foi realizada uma análise visual em imagem de satélite (Google Earth) referente ao ano de 2015 com a finalidade de avaliar o uso e ocupação dos solos preponderantes nas áreas de maior potencialidade de aptidão para implantação dos referidos empreendimentos. Ademais, para a escolha das áreas preferenciais para implantação de aterros, optou-se por áreas com distanciamento em mais de 500 metros de núcleos populacionais, como indicado pela norma NBR 15849 (ABNT, 2010). Assim, foram indicadas as áreas preferenciais para implantação de aterros, com níveis de aptidão médios, em áreas ocupadas por plantações de cana de açúcar. As áreas próximas foram avaliadas para a implantação dos demais módulos da CTRS para facilitar as questões logísticas do empreendimento. Esta avaliação foi realizada a partir da análise do mapa de potencialidade de aptidão para incineradores, do uso e ocupação dos solos e das direções principais dos ventos.

Para tal, foi elaborado o diagrama de rosetas com as frequências e direções dos ventos com o auxílio do software RockWorks14.

A avaliação dos ventos e da possível dispersão de poluentes por incineradores foi feita visando minimizar ou tornar público o eventual carreamento de poluentes atmosféricos frontais aos núcleos populacionais da região, levando-se em conta o histórico eólico do período 2008 - 2016 e a posição dos núcleos populacionais próximos, inseridos no raio de 25 $\mathrm{km}$ a partir do centro de Santa Cruz da Conceição.

\section{RESULTADOS E DISCUSSÕES}

A figura 14 exibe a sugestão para os locais preferenciais para implantação de aterros (em vala e em camada) e dos locais para a implantação da Central de Tratamento de Resíduos Sólidos, incluindo o incinerador para o município de Santa Cruz da Conceição. O mapa mostra detalhes de uso e ocupação através da imagem de satélite referente ao ano de 2017. São sugeridas duas áreas para implantação de aterros em camadas (a nordeste) e uma área para aterros em valas, além de se exibir os locais preferenciais para a implantação dos demais possíveis módulos da CTRS. As áreas sugeridas para a implantação da CTRS estavam ocupadas em 2015 por plantações de cana-de-açúcar e plantações de madeiras para reflorestamento.

Os resultados expressos foram considerados satisfatórios e demostram que a metodologia adotada favoreceu e auxiliou o discernimento para a escolha das melhores áreas para a implantação da CTRS.

Em relação aos aterros sanitários, a metodologia adotada permitiu a escolha de áreas com as seguintes características: baixa permeabilidade, alta estabilidade geotécnica, média resistência a erosão, declividades adequadas aos tipos de aterros em vala e em camada, áreas com ausência de fragmentos de vegetação e distantes em mais de 200 metros de corpos hídricos; além disso, tais áreas são dotadas de infraestrutura viária e estão distantes em mais de 500 metros de aglomerados populacionais, sendo ocupadas atualmente por plantações de cana-de-açúcar. Ademais, respeitam a legislação municipal representada pelo plano diretor municipal. Os locais sugeridos apresentam interferência com núcleos de áreas de gerenciamento de risco aviário (AGRAs) não prioritárias relacionada ao aeródromo Civil de Pirassununga. Desta maneira, é recomendado no caso de implantação das unidades de aterros sanitários, que sejam seguidas as normas técnicas de operação e a legislação expressa pela Política Nacional de Resíduos Sólidos. Assim, será evitada qualquer possibilidade de atração de aves e ficará resguardada a segurança da aviação civil e militar presentes na região.

Levando-se em consideração que a gestão dos resíduos no município venha a atender rigorosamente a legislação brasileira, destaca-se que existe baixíssimo potencial de atração de aves uma vez que apenas rejeitos iriam para os referidos aterros. Resíduos orgânicos que apresentam alta potencialidade de atração não devem ser destinados ao aterro sanitário e sim tratados em biodigestores. 


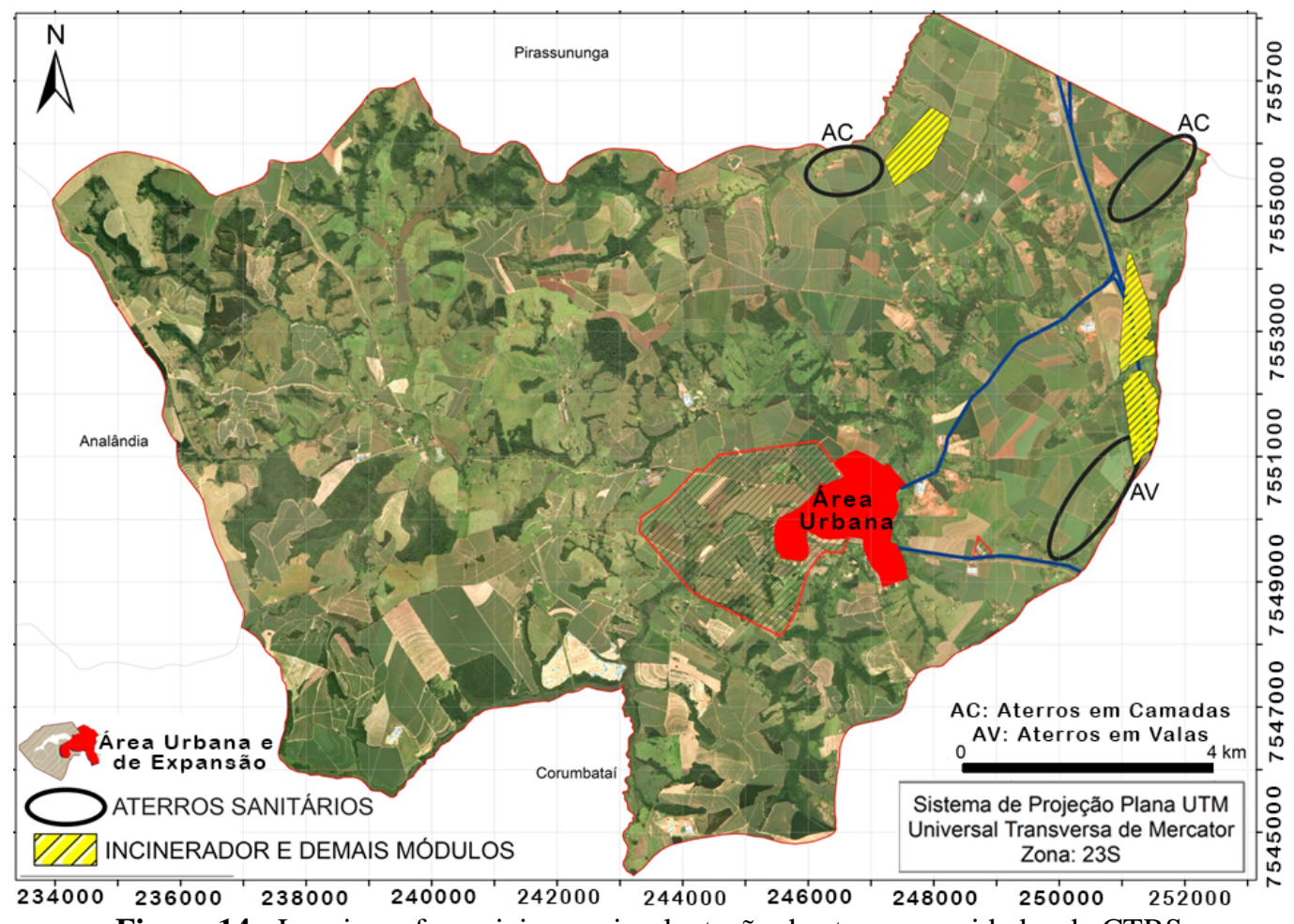

Figura 14 - Locais preferenciais para implantação de aterros e unidades da CTRS.

A metodologia empregada para a identificação de locais adequados à implantação de incineradores e os demais possíveis módulos da CTRS se mostrou também satisfatória.

O mapa de potencialidade possibilitou um discernimento coerente entre as áreas do município e favoreceu a escolha das áreas com as características mais adequadas.

Os locais sugeridos para a implantação da CTRS estão localizados em zonas destinadas à implantação de indústrias e na área rural do município, além de não apresentarem fragmentos de vegetação natural e áreas de preservação permanente. Situam-se em locais estrategicamente logísticos, com acesso a rodovias e distam-se em mais de 600 metros de núcleos populacionais.

Em etapa posterior, com o auxílio do diagrama com a direção e frequência dos ventos foi possível avaliar a probabilidade de ocasionar carreamento de poluição atmosférica em direções frontais aos aglomerados humanos regionais (raio de $25 \mathrm{~km}$ do centro de Santa Cruz da Conceição).

As áreas sugeridas em rosa evitam em mais de $64 \%$ os ventos frontais em direções aos núcleos populacionais humanos regionais. Apenas $12 \%$ dos ventos costumam se direcionar para Leme, e $24 \%$ se direcionam para Santa Cruz da Conceição, atingindo a cidade em porções distintas, dependendo da direção preferencial do vento momentâneo.

Caso ocorra a instalação dos módulos da CTRS no local, é recomendado que o incinerador fique a 60 metros distante da rodovia.

Destaca-se também que a área indicada se localiza a mais de $3,5 \mathrm{~km}$ de distância da área urbana de Santa Cruz da Conceição, a mais de $4,5 \mathrm{~km}$ de Leme e a mais de $8 \mathrm{~km}$ de Pirassununga.

Já as áreas sugeridas em amarelo evitam em mais de $67 \%$ dos ventos frontais em direção aos núcleos populacionais próximos (Pirassununga a $4,5 \mathrm{~km}$, Leme a $10,5 \mathrm{~km}$ e Santa Cruz da Conceição a $5 \mathrm{~km}$ ).

Destaca-se que as áreas com menor permeabilidade são mais favoráveis à implantação da CTRS uma vez que podem favorecer a proteção de recursos hídricos contra contaminação por efluentes oriundos do empreendimento. Caso a CTRS venha a ser implantada deve-se atentar a esta observação.

A metodologia adotada para aterros e incineradores optou por tornar inaptas as áreas com presença de fragmentos de vegetação naturais, uma vez que as áreas de reserva legais estão com níveis de preservação inadequados.

Desta forma a metodologia adotada visa proteger os recursos biológicos naturais, uma vez que o referido município se encontra em déficit legal quanto a esta questão. 


\section{CONCLUSÕES}

Este estudo demonstrou que a combinação de informações advindas da compartimentação fisiográfica e do sensoriamento remoto balizadas por critérios científicos, técnicos e legais, e à luz das características de uma CTRS - permite, em ambiente computacional, a identificação exitosa e expedita de áreas potencialmente aptas à instalação deste tipo de empreendimento.

Ademais, o método adotado subsidia a gestão ambiental, pois diminui a intensidade de conflitos e favorece o ordenamento territorial sustentável. O know-how desenvolvido neste trabalho pode ser aplicado a qualquer território, em projetos envolvendo consórcios municipais ou um único município, em complemento às iniciativas que visam resolver a dramática questão do acentuado acúmulo e dispersão de resíduos sólidos urbanos na natureza.

Portanto, a implantação de uma CTRS e respectivos aterros sanitários, a partir de um consórcio intermunicipal, contribuiria de forma marcante para sanar o déficit ambiental relacionado à gestão dos resíduos sólidos do próprio município e da região.

Em Santa Cruz da Conceição foram identificadas seis áreas adequadas para a implantação de aterros e CTRS: duas delas têm características apropriadas para implantação de aterros em camadas, outra para aterro em valas e três para a implantação da CTRS, incluindo incineradores. Tais áreas, com potencial para concentrar e tratar grandes volumes de resíduos sólidos, estão distribuídas na parte leste do município que tem, ainda, a vantagem de ser contemplada por excelente malha viária. Recomenda-se que, no caso de concretização da presente proposta, estudos de maior detalhamento sejam realizados para as áreas preferenciais indicadas no presente estudo, o que incluiria levantamento topográfico e ensaios geotécnicos, visando a obtenção de maior precisão com referência aos parâmetros de permeabilidade e declividade.

\section{REFERÊNCIAS}

ABNT - Associação Brasileira de Normas Técnicas. NBR 15849. Resíduos sólidos urbanos - Aterros sanitários de pequeno porte - Diretrizes para localização, projeto, implantação, operação e encerramento. Rio de Janeiro: ABNT, 2010.

ABRELPE - Associação Brasileira de Empresas de Limpeza Pública e Resíduos Especiais. Panorama dos Resíduos Sólidos no Brasil 2015. 2016. 92p. Disp. em: http://www. abrelpe.org.br/Panorama/panorama2015.pdf. Acessado em: mar. 2016.

ARAÚJO, R.T. Zoneamento Ecológico-Econômico do município de Santa Cruz da Conceição - SP: uma proposta conceitual de planejamento para a sustentabilidade local. São Carlos, 2008, 95p. Tese (Doutorado em Ciências), Centro de Ciências Biológicas e da Saúde - Universidade Federal de São Carlos,

BRASIL. Ministério do Meio Ambiente, Conselho Nacional de Meio Ambiente (CONAMA). Resolução CONAMA n ${ }^{\circ}$ 316 , de 29 de outubro de 2002. Dispõe sobre procedimentos e critérios para o funcionamento de sistemas de tratamento térmico de resíduos. Disp. em: http://www.mma.gov. br/port/conama/res/res02/res31602.html. Acessado em: 12 dez. 2015

BRASIL. Lei $n^{\circ} \mathbf{1 2 . 3 0 5}$ de 2 de agosto de 2010. Política Nacional de Resíduos Sólidos. Diário Oficial da República Federativa do Brasil, Poder Executivo, Brasília, DF, 3 de agosto de 2010. Seção 1, p. 3.

BRASIL. Portaria no 249/GC5 de 6 de maio de 2011. Aprova a edição do PCA 3-2, que dispões sobre o Plano Básico de Gerenciamento do Risco Aviário - PBGRA nos aeródromos brasileiros. Comando da Aeronáutica. Ministério da Defesa. 2011.

BRASIL. Lei $\mathbf{N}^{\mathbf{0}} \mathbf{1 2 . 6 5 1}$, de 25 de maio de 2012. Dispõe sobre a proteção da vegetação nativa. Diário Oficial da República Federativa do Brasil, Poder Executivo, Brasília, DF, 25 de maio de 2012.
BRASIL. Ministério dos Transportes. Base de dados georreferenciados PNLT. 2015. Disp. em: http://www.transportes.gov.br/conteudo/2822-base-de-dadosgeorreferenciados-pnlt-2010.html. Acessado em: 13 nov. 2015.

BRITO, H.D. Mapeamento geoambiental como subsídio à seleção de áreas para implantação de Centrais de Tratamento de Resíduos Sólidos Urbanos: aplicação ao município de Santa Cruz da Conceição-SP. Rio Claro, 2016. 156p. Dissertação (Mestrado em Geociências e Meio Ambiente), Instituto de Geociências e Ciências Exatas, Universidade Estadual Paulista.

CEPAGRI - Centro de Pesquisas Meteorológicas e Climáticas Aplicadas à Agricultura. Clima dos Municípios Paulistas. 2015. Disp. em: http://www.cpa.unicamp.br/outras-informacoes/cli ma_muni_519.html. Acessado em: 23 nov. 2014.

ESRI. ArcGIS Desktop: Release 10.1. Redlands, CA: Environmental Systems Research Institute. 2015.

FIORI, A.P. Metodologias de Cartografia Geoambiental. In: Simpósio Brasileiro de Cartografia Geotécnica e Geoambiental, 5, 2004, São Carlos. Anais... São Carlos: ABGE, CD-ROM.

GOMES, P.C.B. (Org.). Plano da bacia hidrográfica do Rio Mogi Guaçu. São Carlos: Suprema, 300p., 2003,

IBGE - Instituto Brasileiro de Geografia e Estatística. Folha Corumbataí. São Paulo: IBGE, 1971a. SF-23-Y-A-II-1. Escala 1:50.000

IBGE - Instituto Brasileiro de Geografia e Estatística. Folha Leme. São Paulo: IBGE, 1971b. SF-23-Y-A-I-2. Escala 1:50.000.

IBGE - Instituto Brasileiro de Geografia e Estatística. Malha municipal 2010. Disp. em: ftp://geoftp.ibge.gov.br/ malhas _digitais/municipio_2010/. Acessado em: 08 out. 2015.

IG - Instituto Geológico do Estado de São Paulo. Folha Leme. São Paulo: IG, 1980. SF-23-Y-A-II-1. Escala 1:50.000.

IG - Instituto Geológico do Estado de São Paulo. Folha Corumbataí. São Paulo: IG, 1984. SF-23-Y-A-I-2. Escala 
$1: 50.000$

IG - Instituto Geológico do Estado de São Paulo. Metodologia para Seleção de Áreas para Tratamento e Disposição Final de Resíduos Sólidos. In: BROLLO, M.J. \& SILVA, P.C.F. (coord.) Relatório Técnico. São Paulo: IG / SMA, 1999.

IRITANI, M.A. \& EZAKI, S. As águas subterrâneas do Estado de São Paulo. São Paulo: SMA, 104p., 2012.

KARMANN, I. Ciclo da água - Água subterrânea e sua ação geológica. In: Teixeira, W.; Toledo, M.C.M.; Fairchild, T.R.; TaiolI, F. (Orgs.). Decifrando a Terra. 1 ed. São Paulo: Oficina de Textos, 568p.

KÖPPEN, W. Klimate der Erde. Gotha: Verlag Justus Perthes. 1948.

LEVINE, S.C. Projetos e Critérios para Localização de Aterros Sanitários. In: Transportation, Water and Urban Development Department, World Bank Urban No. UE-12, 3, 1996.

MMA - Ministério do Meio Ambiente. Cadastro Nacional de Unidades de Conservação. 2016. Disp. em: http://mapas. mma.gov.br/i3geo/mma/openlayers.htm?n1cgtd05gujrconr25 cj4ukpk6. Acessado em: 05 jan. 2016.

OAS - Organization of American States. Guarani Aquifer System: Environmental Protection and Sustainable Development of the Guarani Aquifer System. Water Project Series, n. 7, 2005.

OLIVEIRA, T.A. Compartimentação fisiográfica aplicada à avaliação de terrenos: subsídio ao planejamento territorial do município de Cananéia-SP. 2004. Rio Claro. Dissertação (Mestrado em Geociências e Meio Ambiente)Instituto de Geociências e Ciências Exatas, Universidade Estadual Paulista.

PEREZ, Z.M.L. (coord.). Panorama dos Resíduos Sólidos do Estado de São Paulo. Versão preliminar. São Paulo: CETESB, 2013.

REIS, F.A.G.V. \& CERRI, L.E.S. (coords.). Metodologia para avaliação de áreas sujeitas à ocorrência de ondas de cheia e corridas de massa/detritos: Estudo piloto no duto OSBRA no Estado de São Paulo. Relatório final de pesquisa, 2014
ROSS, J.L.S. \& MOROZ, I.C. Mapa geomorfológico do Estado de São Paulo. USP/IPT/FAPESP. Escala 1:500.000, 1997.

SANTA CRUZ DA CONCEIÇÃO. Lei complementar no 14, de 27 de novembro de 2007. Dispõe sobre o Plano Diretor estratégico do município de Santa Cruz da Conceição - SP e dá outras providências. Disp. em: http://www.santacruzda conceicao.sp.gov.br/novo site/plano diretor/planodiretor/ 2013/20130702161619.pdf. Acessado em: 20 out. 2015.

SIGRH - Sistema de Informações para o Gerenciamento de Recursos Hídricos do Estado de São Paulo. Banco de Dados Pluviométricos do Estado de São Paulo. 2013. Disp. em: http://www.sigrh.sp.gov.br. Acessado em: 18 set. 2015.

USP - Universidade de São Paulo. Laboratório de Ciências Agrárias. Dados da Estação Meteorológica da USP Campus Pirassununga. 2016. Disp. em: http://www.agra riasusp.com.br/agrariasusp01/estacao.html. Acessado em: 11 jun. 2016.

WILSON, D.C. (coord.). Global Waste Management Outlook. Viena: International Solid Waste Association General Secretariat. 2015.

ZAINE, J.E. Método de Fotogeologia aplicado a estudos geológico-geotécnicos: ensaio em Poços de Caldas, MG. 2011. Rio Claro. Tese (Livre docência em Geociências e Meio Ambiente), Instituto de Geociências e Ciências Exatas, Universidade Estadual Paulista.

ZUQUETTE, L.V.; PEJON, O.J., SINELLI, O.; GANDOLFI, $\mathrm{N}$. Methodology of specific engineering geological mapping for selection of sites for waste disposal. In: In: INTERNATIONAL CONGRESS OF THE INTERNATIONAL ASSOCIATION OF ENGINEERING GEOLOGISTS, 7, 1994, Lisboa. Anais... Lisboa: CRC Press, 1994, p. 2481-2489.

Submetido em 24 de fevereiro de 2017 Aceito em 14 de julho de 2018 